EMBRYARIDDLE
Aeronautical University

SCHOLARLY COMMONS
International Journal of Aviation, Aeronautics, and Aerospace

\title{
Low thrust and low power propulsion systems options for small satellites
}

\author{
Redha Amri \\ University of Blida - Algeria, amri_redha@yahoo.co.uk
}

Follow this and additional works at: https://commons.erau.edu/ijaaa

Part of the Systems Engineering and Multidisciplinary Design Optimization Commons

\section{Scholarly Commons Citation}

Amri, R. (2020). Low thrust and low power propulsion systems options for small satellites. International Journal of Aviation, Aeronautics, and Aerospace, 7(3). https://doi.org/10.15394/ijaaa.2020.1510

This Article is brought to you for free and open access by the Journals at Scholarly Commons. It has been accepted for inclusion in International Journal of Aviation, Aeronautics, and Aerospace by an authorized administrator of Scholarly Commons. For more information, please contact commons@erau.edu. 
The growing competitiveness in the commercial space market has raised the interest in operating small spacecraft at very low altitudes. To make this feasible, the space industry has started developing propulsion options tailored specifically to these platforms (Leomanni et al., 2017). Small satellite propulsion systems present many design problems because of the need to minimize the system size, weight, and low power consumption. Propulsion systems that are characterised by low thrust and low electrical power consumption have been used for small satellites, these systems required for orbit correction, circularization after separation from the launcher, station keeping or orbit maintenance, local time ascending node (LTAN) correction, and de-orbiting at the end of life of the satellite. To make a start-up in space technologies in Algeria, the Centre of Space Techniques (CTS) has initiated a number of microsatellite projects. For this reason, research works are being performed for the design and development of low power and low thrust propulsion systems (Amri \& Gibbon, 2012; Amri et al., 2013). The first Algerian micro-satellite, named Alsat-1, was equipped by a butane propulsion system using low power (15 watts) resistojet thruster with $2.3 \mathrm{~kg}$ of propellant.

The liquefied butane gas was selected due to its higher storage density and safety compared to the other propellants used on microsatellites. The system provides an average specific impulse and thrust level of 99.9 seconds and 48.8 milli newton respectively (Amri \& Gibbon, 2012). Actually, small number of low thrust propulsion systems have been used and flown on board small satellites, as xenon and nitrogen cold gas systems, nitrous oxide, and butane thermal propulsion systems. A monopropellant system is another good option for low thrust and power for small satellites. Hydrazine liquid is the most used as monopropellant, however hydrazine is a very toxic and inflammable substance that has an implication on the security of the persons during testing of the system. Actually, many researches have undertaken processes to replace liquid hydrazine as monopropellant. Hydrogen peroxide and nitrous oxide propellants can be alternative monopropellants for application in future missions, and this is due to their lower toxicity and safety (Amri et al., 2013; Jo, 2017; Zakirov, 2001). The technology of $\mathrm{H}_{2} \mathrm{O}_{2}$ monopropellant can be used as an oxidizer for bipropellants (Amri \& Rezoug, 2011; Moon \& Kwon, 2014). The current paper aims to study low thrust propulsion systems: cold gas, thermal, and monopropellant propulsion systems in order to estimate its performance. Most of propellants that can be used for these propulsion systems were taken into account in this study.

\section{Propulsion System Design}

During the design of any propulsion system, the propulsion engineer goes by many steps and decisions before evaluating and achieving the final design of the system. Among these decisions: 
- System selection,

- Propellant and pressurant selection,

$\circ$ Tank storage conditions,

- Thruster dimensions.

O

For the design of low thrust propulsion system, it is important to have a complete knowledge about the design parameters and the performance of thermal, cold gas, and monopropellant propulsion systems. The aim of the present work is to study these types of propulsion systems (cold gas, thermal and monopropellant) with the most propellants used for space propulsion. The design parameters calculated for thermal propulsion are: specific impulse, $C^{*}$, isentropic parameters $(\gamma)$ and the temperature after heating as function of consumed heat which characterise the electrical power of the resistojet. For monopropellants, the parameters are: Isp, $\mathrm{C}^{*}, \gamma$, product composition, molecular mass and the decomposition temperature of $\mathrm{N}_{2} \mathrm{H}_{4}, \mathrm{H}_{2} \mathrm{O}_{2}$, and $\mathrm{N}_{2} \mathrm{O}$ after passing through a catalyst. At the end of this work, simple software was produced for the analysis and the design of the propulsion systems.

\section{Cold Gas and Thermal Propulsion System}

This section is dedicated to the study of cold gas and thermal propulsion systems. Figure 1 shows a general architecture of the system and the resistojet thruster, the main three parts of the system are: tank, valve for open/close the system and a resistojet to provide the electric power to the fluid. A thermal propulsion system uses an electric heater (resistojet) for heating propellant and increasing its thermal energy, which is then accelerated through a converging/diverging nozzle to develop thrust. A cold-gas propulsion system uses the pre-stored energy of a compressed gas without heating the propellant to develop thrust. Many gases and liquids have been taken into account in this study, Oxygen $\left(\mathrm{O}_{2}\right)$, Nitrogen $\left(\mathrm{N}_{2}\right)$, Hydrogen $\left(\mathrm{H}_{2}\right)$, Carbon dioxide $\left(\mathrm{CO}_{2}\right)$, Helium $(\mathrm{He})$, Xenon $(\mathrm{Xe})$, Methane $\left(\mathrm{CH}_{4}\right)$, Propane $\left(\mathrm{C}_{3} \mathrm{H}_{8}\right)$ and Butane $\left(\mathrm{C}_{4} \mathrm{H}_{10}\right)$. 


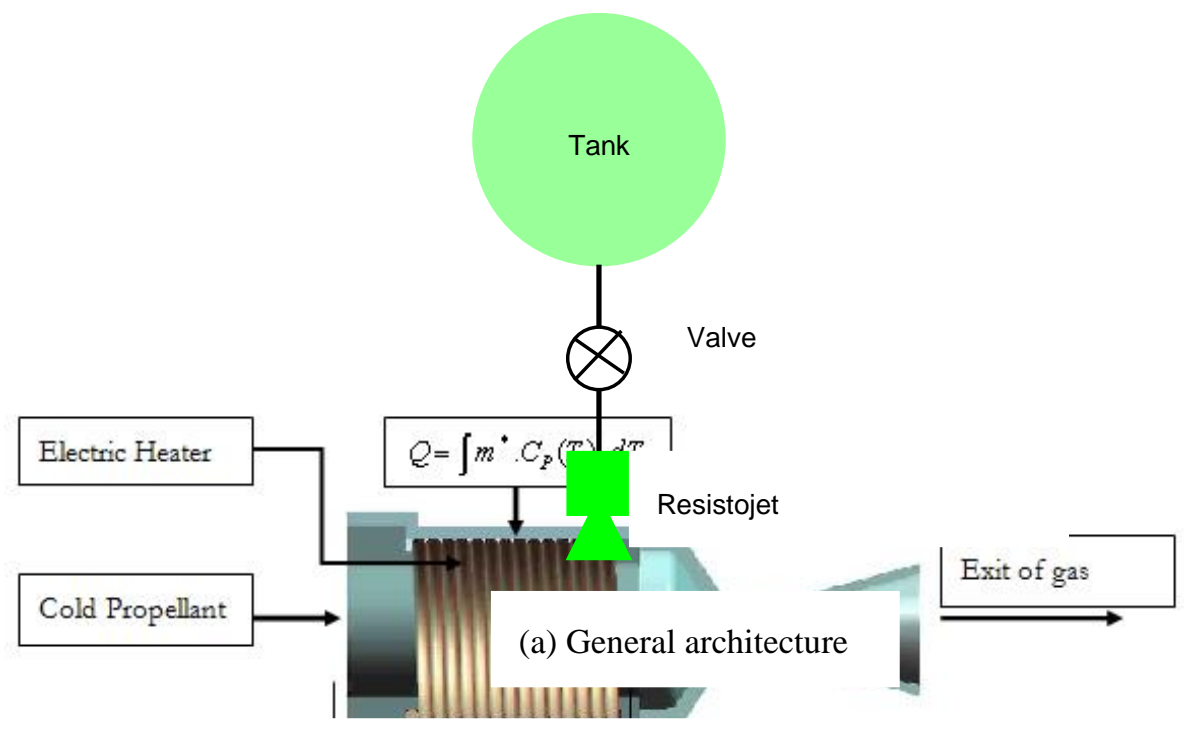

(b) Resistojet thruster

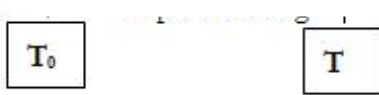

Figure 1. (a) General architecture, (b) Resistojet thruster.

\section{Analysis Method}

The first law of thermodynamics gives:

$$
W+Q=\Delta H
$$

Where: $\mathrm{Q}$ is the electric power of the resistojet used to heat the propellant. For Isentropic and steady fluid flow, heating the propellant at constant pressure can be written as:

$$
Q=\int m^{*} \cdot C_{P}(T) \cdot d T
$$

Where:

$\mathrm{m}^{*}$ : mass flow rate,

$\mathrm{Cp}$ : specific heat at constant pressure,

Q: electric power of the resistojet.

$\mathrm{T}_{0}$ : Propellant storage tank temperature \& temperature at the inlet of the resistojet, $\mathrm{T}$ : Temperature after heating.

\section{Heating (Step 1):}

Using the equation (2), we can compute numerically the propellant temperature (T) after heating for given resistojet power (Q). The heat capacities of 
gases (Cp) are determined by Gordon and McBride method at different temperatures:

$$
\frac{C_{p}}{R}=a_{1}+a_{2} T+a_{3} T^{2}+a_{4} T^{3}+a_{5} T^{4}
$$

Equation (2) can be applied only for a simple gas. In some cases, the propellant can be used as liquid (example Butane), in this case the resistojet is used for two reasons: (a) vaporise the liquid propellant, (b) heat the gas propellant. Equation 3 presents the general formula for heating liquid propellant at constant pressure. Figure 2 gives the explanation of this equation.

$$
Q=\int_{T 0}^{T s a t, P s a t} m^{*} \cdot C_{P, \text { liquide }}(T) \cdot d T+\left[L v \cdot m^{*}\right]_{T s a t, P s a t}+\int_{T s a t, P s a t}^{T} m^{*} \cdot C_{P, G a z}(T) \cdot d T
$$

Where:

$\mathrm{T}_{\text {sat: }}$ saturation temperature,

$\mathrm{P}_{\text {sat: }}$ saturation pressure,

Lv: Latent heat of de vaporisation.

In order to make the analysis, a database for thermodynamic properties of the propellants was generated. This database determines the properties at any temperature and pressure, and it based on mathematical correlations and experimental testing on gases and liquids (Braker \& Mossmann, 1973; Van Wylen, 1973), and it determines propellant phase (gas or liquid), density ( $\rho$ ), compressibility, specific heat of liquid and gas, latent heat of vaporisation, isentropic parameter $(\gamma)$, saturation curve, triple temperature, triple pressure, critical temperature, critical pressure. 


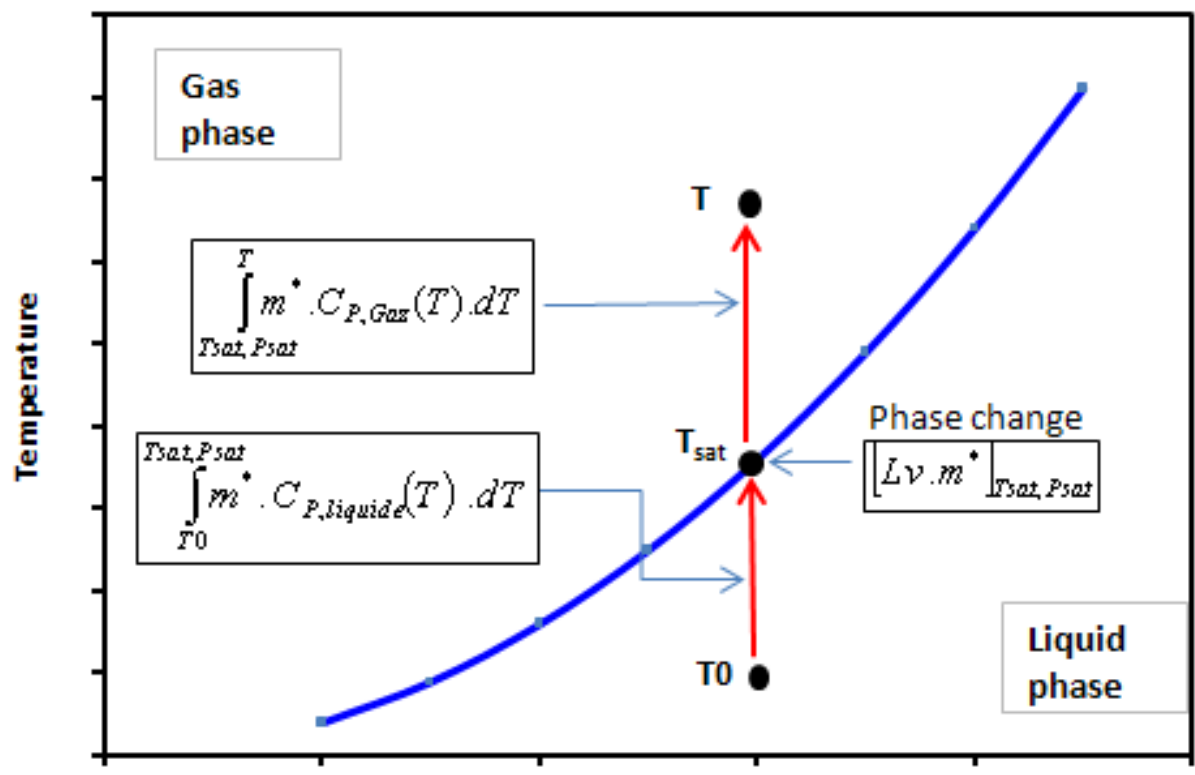

Pressure

Figure 2. Phase diagram shows the heating of liquid propellant at constant pressure.

\section{Performances Using Two Dimensional (2D) Axisymmetric Flow (Step 2)}

After the study of the heating of all the propellants and the determination of all the necessary thermodynamic parameters, the fluid flow inside the nozzle of the resistojet was studied using the FLUENT code. The specific heat $(\mathrm{Cp})$ of the gas was taken variable and change as the temperature change through the nozzle. In this case, Gordon and McBride expressions have been used to calculate the specific heats of gases (Cp). The Euler equations for (2D) axisymmetric inviscid fluid flow inside the nozzle can be written in its vectorial form as follow :

$$
\frac{\partial W}{\partial t}+\operatorname{div}(\phi(W))=0
$$

Where: $W=\left\{\begin{array}{l}\rho \\ \rho u \\ \rho v \\ \rho e\end{array}\right\} \quad \phi=F \cdot i+G \cdot j+H \cdot k$

Where the vectors $F, G, H$ are defined as: 


$$
F=\left\{\begin{array}{l}
\rho u \\
\rho u^{2}+p \\
\rho u v \\
(\rho e+p) u
\end{array}\right\} \quad G=\left\{\begin{array}{l}
\rho v \\
\rho u v \\
\rho v^{2}+p \\
(\rho e+p) v
\end{array}\right\} \quad H=\left\{\begin{array}{l}
0 \\
0 \\
2 p \\
0
\end{array}\right\}
$$

The thermodynamic values (density, pressure, temperature and velocity) of the gas at each point at the exit plane of the nozzle were used to calculate the mass flow rate and the performances of the engine.

For 2D axisymmetric fluid flow, the mass flow rate and the specific impulse can be calculated using the following formulas:

$$
\begin{aligned}
& \int d \dot{m}=\rho_{i} v_{i} \cdot d A_{i} \\
& \dot{m}=\sum \rho_{i} v_{i} \cdot d A_{i} \\
& I_{s p}=\frac{\sum\left(\rho_{i} v_{x i} \cdot d A_{i}\right) \cdot v_{x i}+\sum\left(P_{e}-P_{a}\right) \cdot d A_{i}}{\dot{m} \cdot g}
\end{aligned}
$$

Where: $\left(\mathrm{dA}_{\mathrm{i}}\right)$ is the area element of the exit section of the nozzle as shown in the figure $3, \dot{m}$ is the mass flow rate, $\rho_{i}$ and $v_{x i}$ are the density and the axial velocity at the area element $\left(\mathrm{dA}_{\mathrm{i}}\right)$.

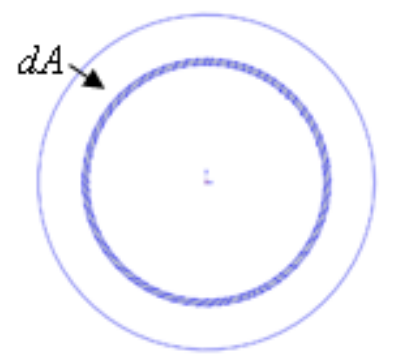

Figure 3. The exit plane of the nozzle.

In this study conic nozzle geometry has been selected with chamber diameter of $10 \mathrm{~mm}$, throat diameter of $0.2 \mathrm{~mm}$ and an expansion ratio of 100. Figure 4 shows the geometry and the mesh of the conic nozzle. 


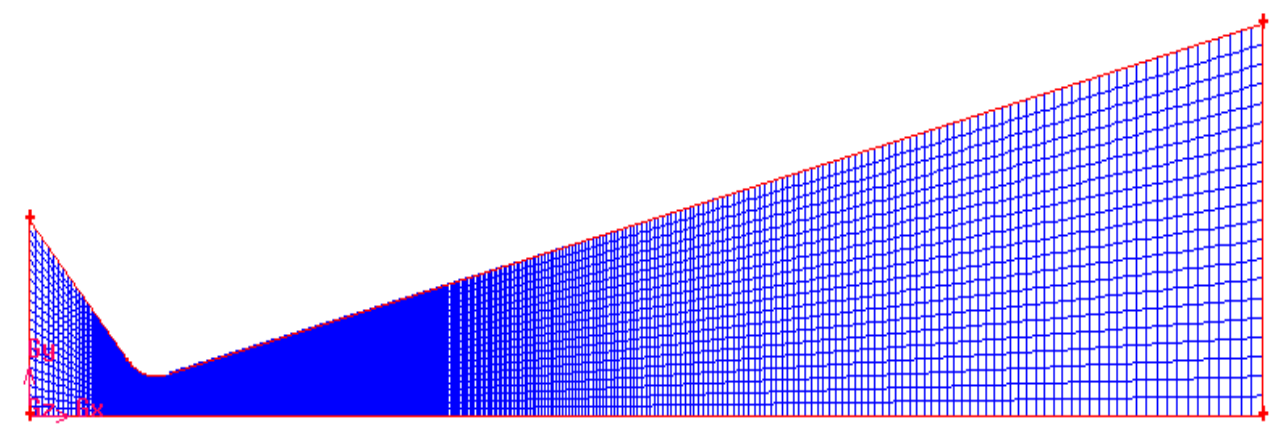

Figure 4. Geometry and mesh of the nozzle (480 x 20).

\section{Results and Discussions}

In this part, some results were presented. Figures 5 to 8 show the results for different propellants used for thermal propulsion. The results given show the vacuum specific impulse (Isp), temperature after heating (T), $\mathrm{C}^{*}$ and isentropic parameter $(\gamma)$ as a function of the consumed heat (or the power of the resistojet). The calculated vacuum specific impulses assume zero ambient pressure.

Figures 5 to 7 show that the temperature, $C^{*}$ and Isp increase as the consumed heat increases. This is evident and during the design of thermal propulsion system, it is necessary to give to this last a higher electric power, which increases the enthalpy of the propellant and consequently the improvement of its performances (specific impulse). On the other hand, low molecular mass propellants (H2, He, CH4) give higher specific impulse (more than 300 second) which is better than some bipropellant systems. However, Xenon has the lower performance because is the heaviest propellant (molecular mass $131 \mathrm{~kg} / \mathrm{Kmol}$ ). From Figure 8, we notice that $\gamma$ decreases with the consumed heat, and this explained by the increase of the temperature due to the resistojet power. 


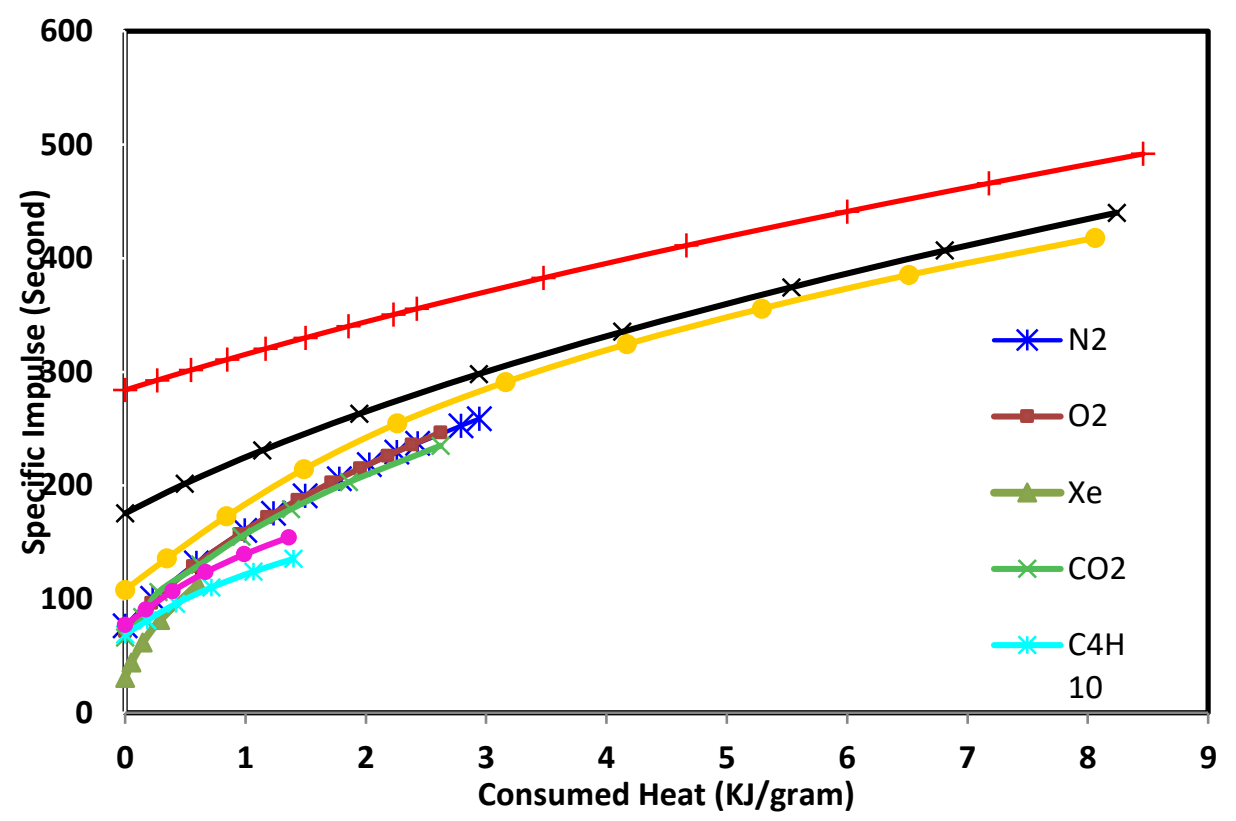

Figure 5. Specific Impulse as function of the consumed heat.

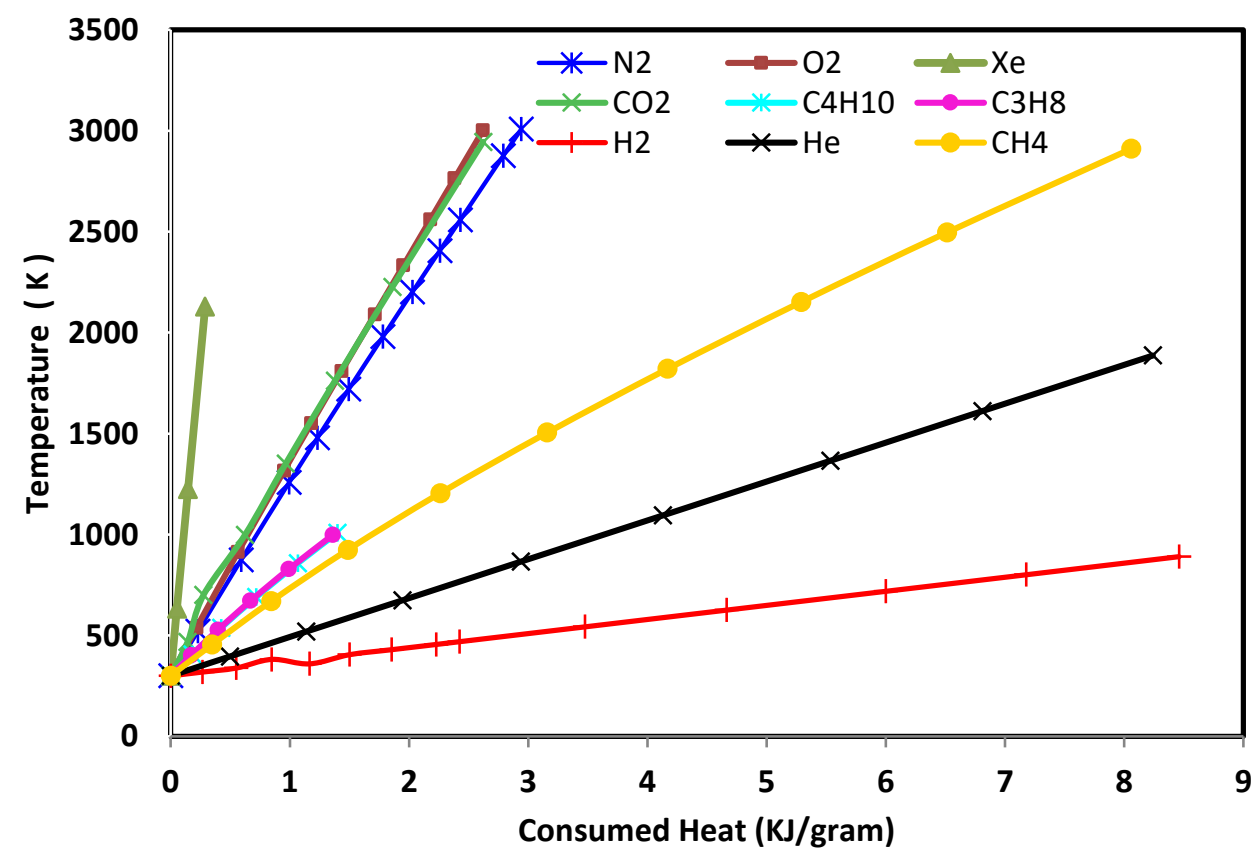

Figure 6. Temperature as function of the consumed heat. 


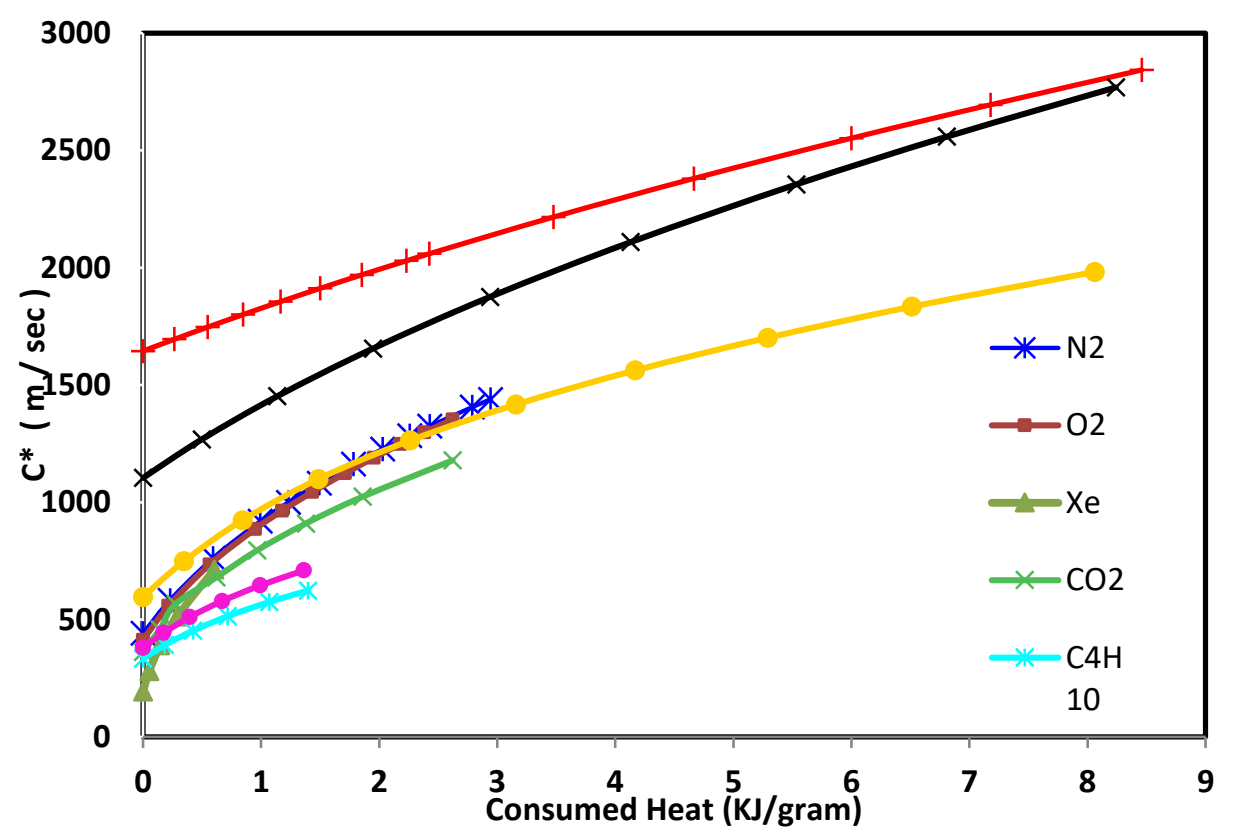

Figure 7. Variation of $\mathrm{C}^{*}$ as function of the consumed heat.

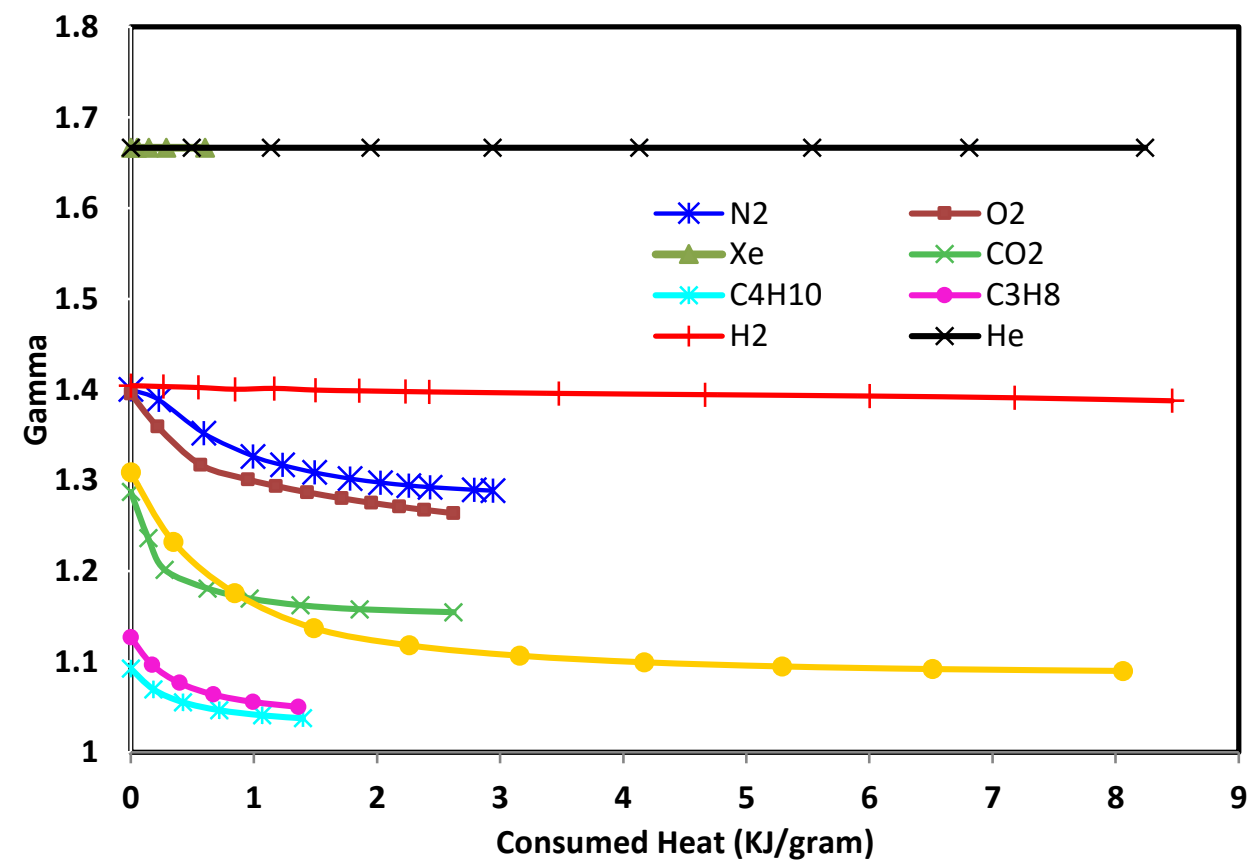

Figure 8. Isentropic parameter $(\gamma)$ as function of the consumed heat. 
For validation, Figure 9 presents some calculated results compared with those obtained by previous researches (Zakirov, 2001). The comparison shows that a good approximation was obtained. Figure 10 presents the calculated values of the specific impulse and density Isp of the propellants used for cold gas propulsion system (without any heat / resistojet power equal zero).

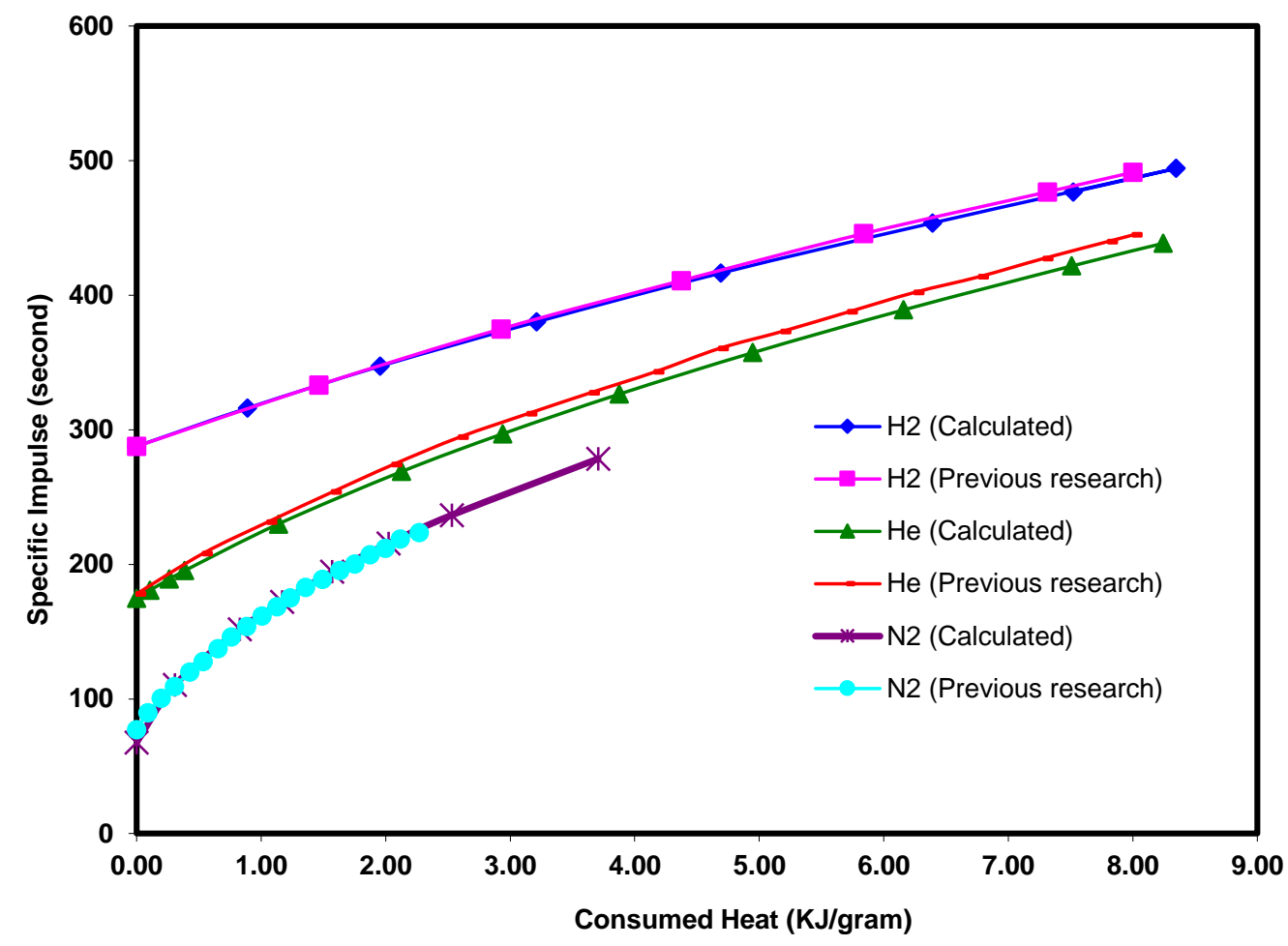

Figure 9. Comparison of the calculated specific impulse with previous research. 


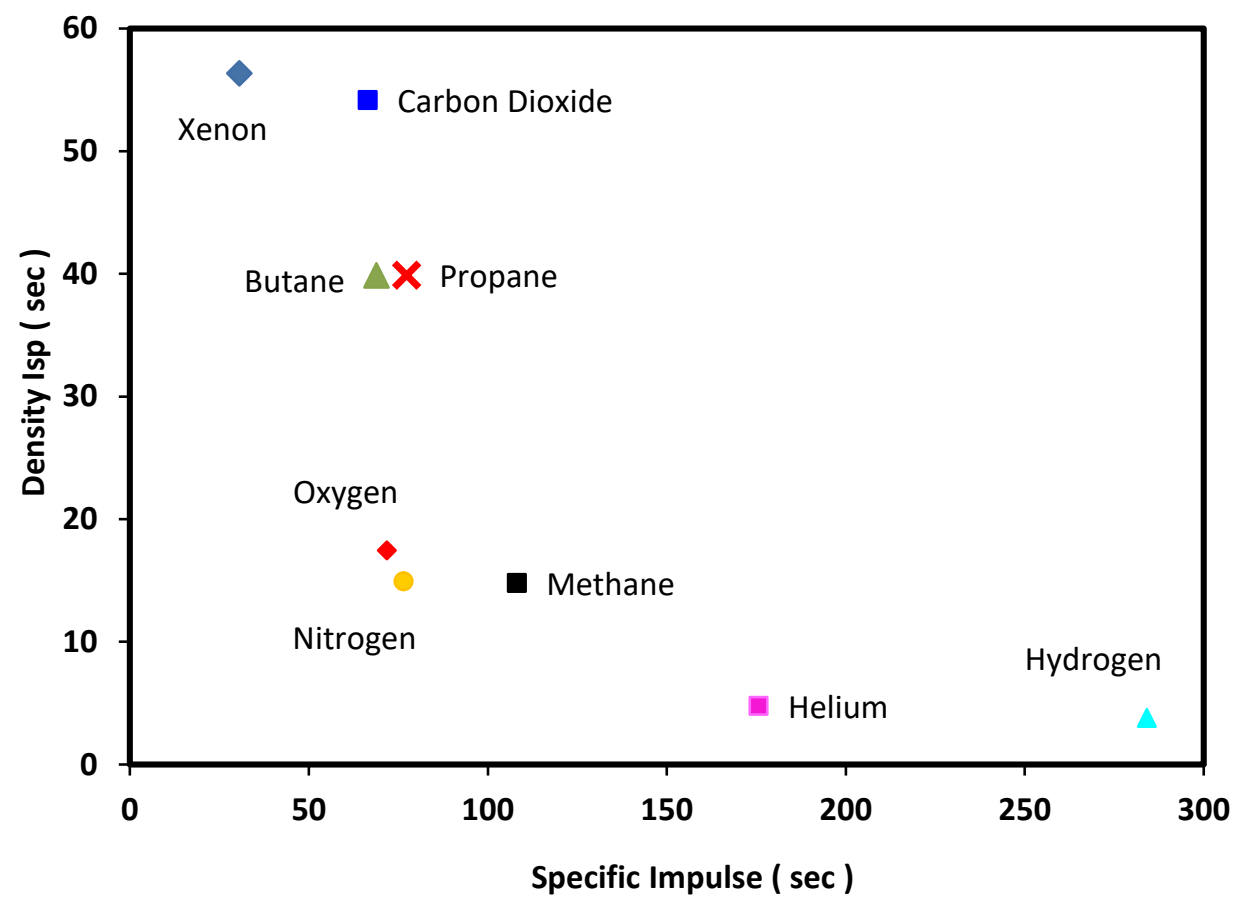

Figure 10. Specific impulse and density Isp of cold gas propulsion systems.

In general, cold gas and thermal propulsion systems are the most used on small satellites, and this due to mass, volume and power limitations. Cold gas propulsion is usually selected for attitude control of the satellite and this is due to its capability of such a system to give a small minimum impulse bit. Heating a propellant in a resistojet ameliorates the specific impulse performance in comparison with cold gas propulsion system. From that point of view, an "ideal" thruster for thermal propulsion (resistojet) would provide the highest specific impulse at minimum power input. Hydrogen is a good propellant because its high specific impulse changes quickly with only little additional heating. However, its low density violates volumetric constraints for small satellites. Helium, nitrogen, nitrous oxide and methane gases store at relatively low density even at high pressures, hence the volume of the propellant tank tends to be large. This can be a problem, as small satellites are typically more volume-constrained than masslimited. Butane is a good propellant for use in microsatellite missions, as it stores as liquid, and hence tankage volume can be reduced (Amri \& Gibbon, 2012; Gibbon, 2002). 


\section{Application}

Alsat-1 thruster (Figure 11) was taken as an example for the analysis. Alsat-1 propulsion system is a butane propulsion system using low power resistojet thruster (15 watts). The system has been engineered such that no liquid phase propellant should be fed to the thruster, in which case the thruster will act as a resistojet, heating the vapour to produce a higher specific impulse (Amri \& Gibbon, 2012). Table 1 gives the geometrical and thermodynamic parameters. Table 2 gives the results (specific impulse and thrust) obtained compared to the real values (flight results of Alsat-1 propulsion system: firing with pipeheater OFF, resistojet 15 watts and fluid flow at steady state).

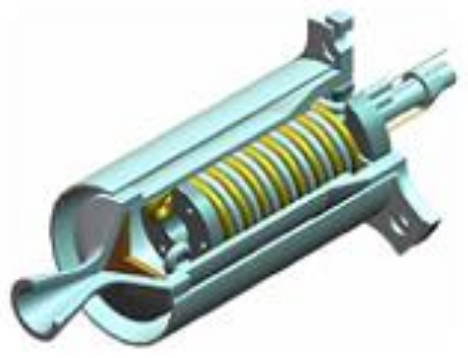

Figure 11. ALSAT-1 propulsion system.

Table 1

Geometrical and Thermodynamic Parameters of Alsat-1 Thruster

\begin{tabular}{|c|c|c|c|}
\hline \multicolumn{2}{|c|}{ Geometrical parameters } & \multicolumn{2}{|c|}{ Thermodynamic parameters } \\
\hline Thruster & Alsat-1 & Propellant & Butane \\
\hline $\begin{array}{l}\text { Chamber diameter } \\
(\mathrm{mm})\end{array}$ & 8.00 & Tank pressure (bar) & 2.00 \\
\hline $\begin{array}{l}\text { Throat diameter } \\
(\mathrm{mm})\end{array}$ & 0.42 & $\begin{array}{l}\text { Tank temperature } \\
(\mathrm{K})\end{array}$ & 300 \\
\hline $\begin{array}{l}\text { Nozzle expansion } \\
\text { ratio }\end{array}$ & $208: 1$ & $\begin{array}{l}\text { Electric } \\
\text { (Watt) }\end{array}$ & 15 \\
\hline
\end{tabular}

Table 2

ALSAT-1 Thruster Results

\begin{tabular}{|l|c|c|}
\hline & Calculated & In Orbit results (Flight) \\
\hline Thrust ( $\mathrm{mN})$ & 58.2 & 54.07 \\
\hline $\begin{array}{l}\text { Specific impulse } \\
\text { (second) }\end{array}$ & 79.49 & 76.56 \\
\hline
\end{tabular}




\section{Monopropellant Propulsion System}

In this part, we present a study of the monopropellant system. The system stores its propellant in tank and feeds it to a decomposition chamber, in which energy (heat) is released through a chemical decomposition. Figure 12 (a) shows a general architecture of the system, it contains: one spherical tank, valve for the opening/closing the system and monopropellant thruster. The propellants taken in consideration are: hydrazine, hydrogen peroxide and nitrous oxide. Actually, hydrazine liquid is the most used for monopropellant system because it gives a good performance. However, hydrazine is a very toxic and inflammable substance that has an implication on the security of the persons during testing of the system. Due to its lower toxicity and safety the hydrogen peroxide was named also as "Green Propellant". Its higher density and better melting point $(-17.9 \circ \mathrm{C})$ than those of hydrazine, makes it as an important propellant that can replace hydrazine. However, its decomposition with time constitutes the major disadvantage of hydrogen peroxide. For nitrous oxide, investigation and studies are currently undertaken to develop nitrous oxide monopropellant thrusters for application in future satellites.

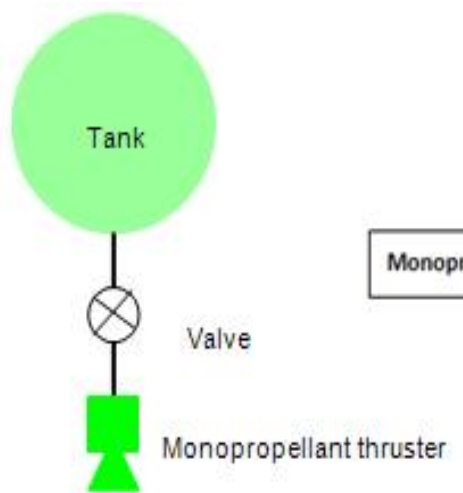

(a)

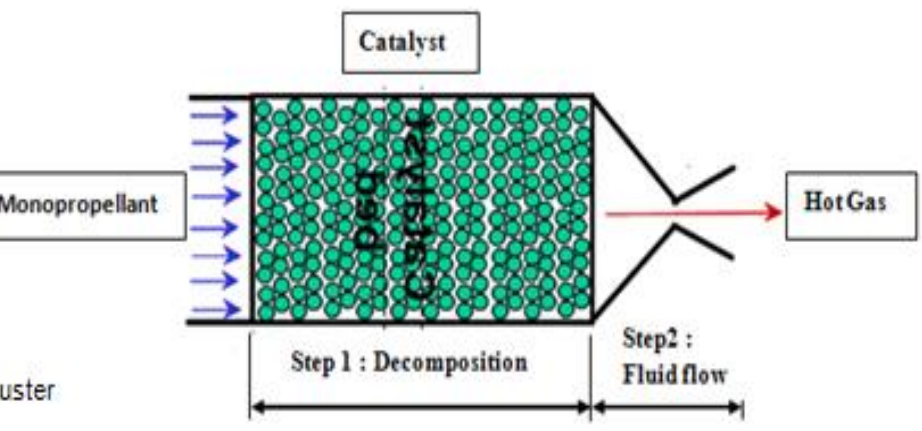

(b)

Figure 12. (a) General architecture of monopropellant system, (b) monopropellant thruster.

\section{Analysis Method}

Figure 12(b) shows the monopropellant thrust, our interest in this part is to study the decomposition of monopropellants (step 1), then fluid flow inside the nozzle (step 2). Three (03) cases of monopropellant decomposition were studied:

- Hydrazine $\left(\mathrm{N}_{2} \mathrm{H}_{4}\right)$ decomposition:

$$
\mathrm{N}_{2} \mathrm{H}_{4}(\mathrm{l}) \rightarrow \mathrm{n}_{\mathrm{p} 1} \mathrm{NH}_{3}+\mathrm{n}_{\mathrm{p} 2} \mathrm{~N}_{2}+\mathrm{n}_{\mathrm{p} 3} \mathrm{H} 2+\mathrm{n}_{\mathrm{p} 4} \mathrm{~N}+\mathrm{n}_{\mathrm{p} 5} \mathrm{H}
$$


Where $\mathrm{n}_{\mathrm{p} i}$ : is the number of mole of the product "i $i$ ". From $\mathrm{n}_{\mathrm{p} 1}$ we can calculate the degree of decomposition of ammonia $\mathrm{NH}_{3}$. Practically, the decomposition of hydrazine is function of the catalyst type, size, geometry and propellant pressure.

Hydrogen peroxide $\left(\mathrm{H}_{2} \mathrm{O}_{2}\right)$ decomposition:

$$
\alpha . \mathrm{H}_{2} \mathrm{O}_{2}(\mathrm{l})+\beta \mathrm{H}_{2} \mathrm{O}(\mathrm{l}) \rightarrow \mathrm{n}_{\mathrm{p} 1} \mathrm{H}_{2} \mathrm{O}+\mathrm{n}_{\mathrm{p} 2} \mathrm{O}_{2}+\mathrm{n}_{\mathrm{p} 3} \mathrm{H} 2+\mathrm{n}_{\mathrm{p} 4} \mathrm{OH}+\mathrm{n}_{\mathrm{p} 5} \mathrm{H}+\mathrm{n}_{\mathrm{p} 6} \mathrm{O}
$$

Where $\alpha$ and $\beta$ are the numbers of moles of $\mathrm{H}_{2} \mathrm{O}_{2}$ and $\mathrm{H}_{2} \mathrm{O}$ respectively.

- Nitrous oxide $\left(\mathrm{N}_{2} \mathrm{O}\right)$ decomposition:

$$
\begin{gathered}
\mathrm{N}_{2} \mathrm{O}(\mathrm{g}) \rightarrow \mathrm{n}_{\mathrm{p} 1} \mathrm{~N}_{2} \mathrm{O}+\mathrm{n}_{\mathrm{p} 2} \mathrm{~N}_{2}+\mathrm{n}_{\mathrm{p} 3} \mathrm{O} 2+\mathrm{n}_{\mathrm{p} 4} \mathrm{NO}+\mathrm{n}_{\mathrm{p} 5} \mathrm{O}+\mathrm{n}_{\mathrm{p} 6} \mathrm{~N} \\
\text { Where } \mathrm{n}_{\mathrm{p} 1} \text { gives the degree of decomposition of } \mathrm{N}_{2} \mathrm{O} \text {. }
\end{gathered}
$$

Calculation of the decomposition temperature

The general energy equation of the decomposition reactions is written by:

$$
\Delta H_{r}^{0}+\sum_{i} n_{\text {pi,reactan } t s} \int_{298}^{T_{0}} C_{p i} d T=\sum_{i} n_{p i, \text { products }} \int_{298}^{T_{d}} C_{p i} d T
$$

Where $\mathrm{C}_{\mathrm{pi}}(\mathrm{T})$ : specific heat at constant pressure of the product element " $\mathrm{i}$ ", determined by Gordon and McBride method at different temperatures. $\Delta H_{r}^{0}$ is the energy difference between the reactants and products under standard conditions $(\mathrm{kJ})$. We should note that at each iteration the calculation of the equilibrium composition of the combustion is needed. The decomposition temperature $\left(\mathrm{T}_{\mathrm{d}}\right)$ can be computed numerically to verify the equation (11). The numerical method used to solve this problem is described in the reference (Amri \& Rezoug, 2011).

After determination of the decomposition temperature and number of moles of the products, molecular mass $(\mathrm{M})$ and isentropic parameter $(\gamma)$ of the decomposition products can be calculated by the following equations:

$$
\begin{aligned}
& M=\frac{\sum_{i} n_{p_{i}} \cdot M_{i}}{\sum_{i} n_{p_{i}}} \quad(12) ; \quad C p=\frac{\sum_{i} n_{p_{i}} \cdot C p_{i}}{\sum_{i} n_{p_{i}}} \\
& \gamma=\frac{C p}{C p-R}
\end{aligned}
$$

R: universal gas constant (8314.41 Joule/Kmol. K)

The fluid flow inside the nozzle is the same as described in section titled Performances Using Two Dimensional (2D) Axisymmetric Flow (Step 2) with frozen flow assumption. 


\section{Hydrazine $\mathrm{N}_{2} \mathrm{H}_{4}$ Monopropellant}

\section{Results and Discussions}

The variation of the specific impulse, the decomposition temperature and $\mathrm{C}^{*}$ as function of the degree of decomposition of ammonia are presented in Figure 13. Figure 14 presents the molecular mass and the isentropic parameter $(\gamma)$ of the decomposition product. Practically, in the presence of a catalyst, hydrazine decomposed into $\mathrm{NH}_{3}$ and $\mathrm{N} 2$. However, the $\mathrm{NH}_{3}$ decomposition is an endothermic reaction, i.e. more the degree of $\mathrm{NH}_{3}$ decomposition increases, and we have:

- The decomposition temperature and specific impulse decreases which make a degradation of the performance for the system, and this due to the ammonia which requires a thermal energy for its decomposition.

- The gases $\left(\mathrm{N}_{2}\right.$ and $\left.\mathrm{H}_{2}\right)$ increase in the composition product.

For that, during the design of hydrazine monopropellant thruster the selection of a catalyst which gives a minimum decomposition of $\mathrm{NH}_{3}$ is desired.

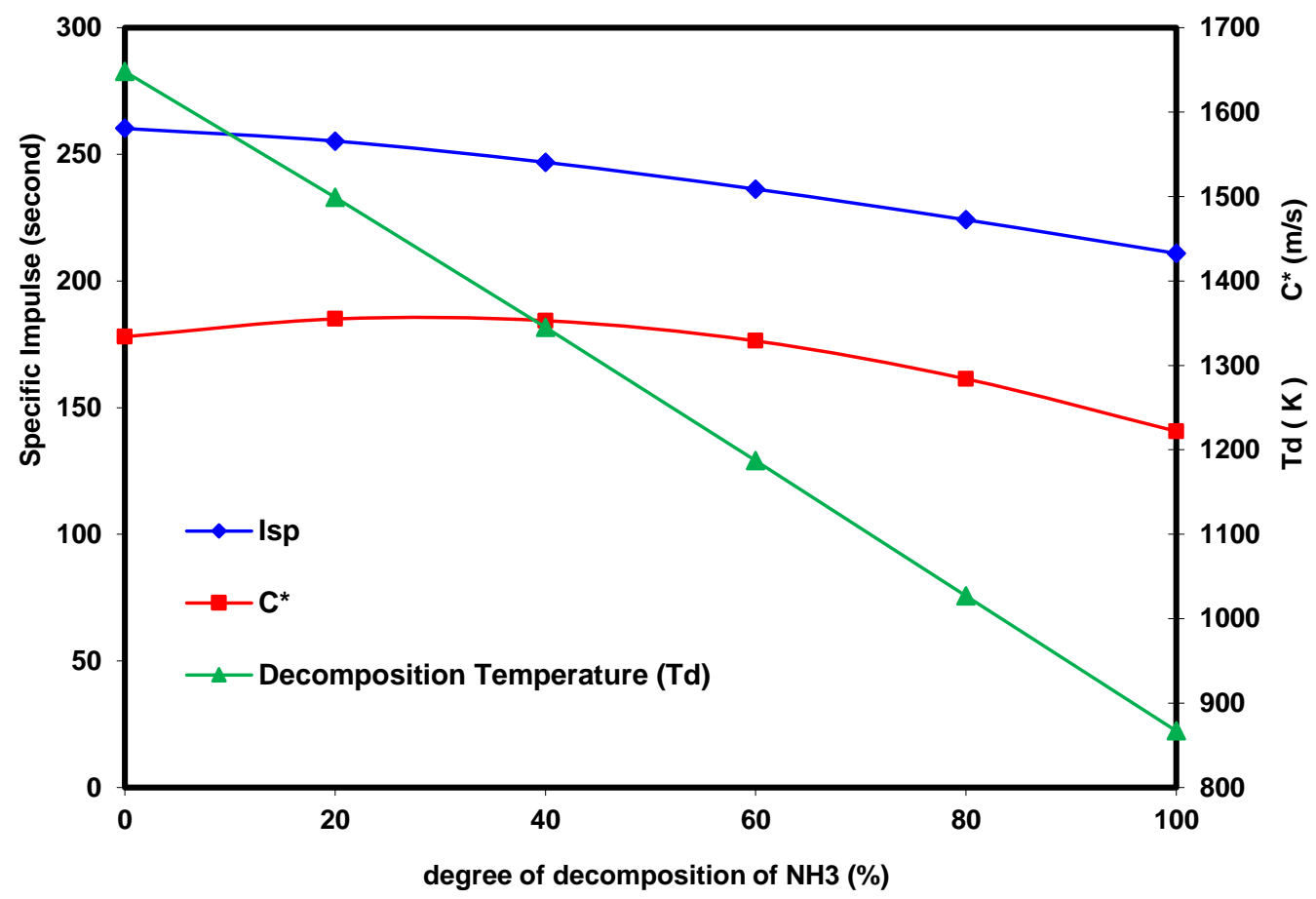

Figure 13. Variation of the decomposition temperature, specific impulse and $\mathrm{C}^{*}$ with the degree of decomposition of ammonia. 


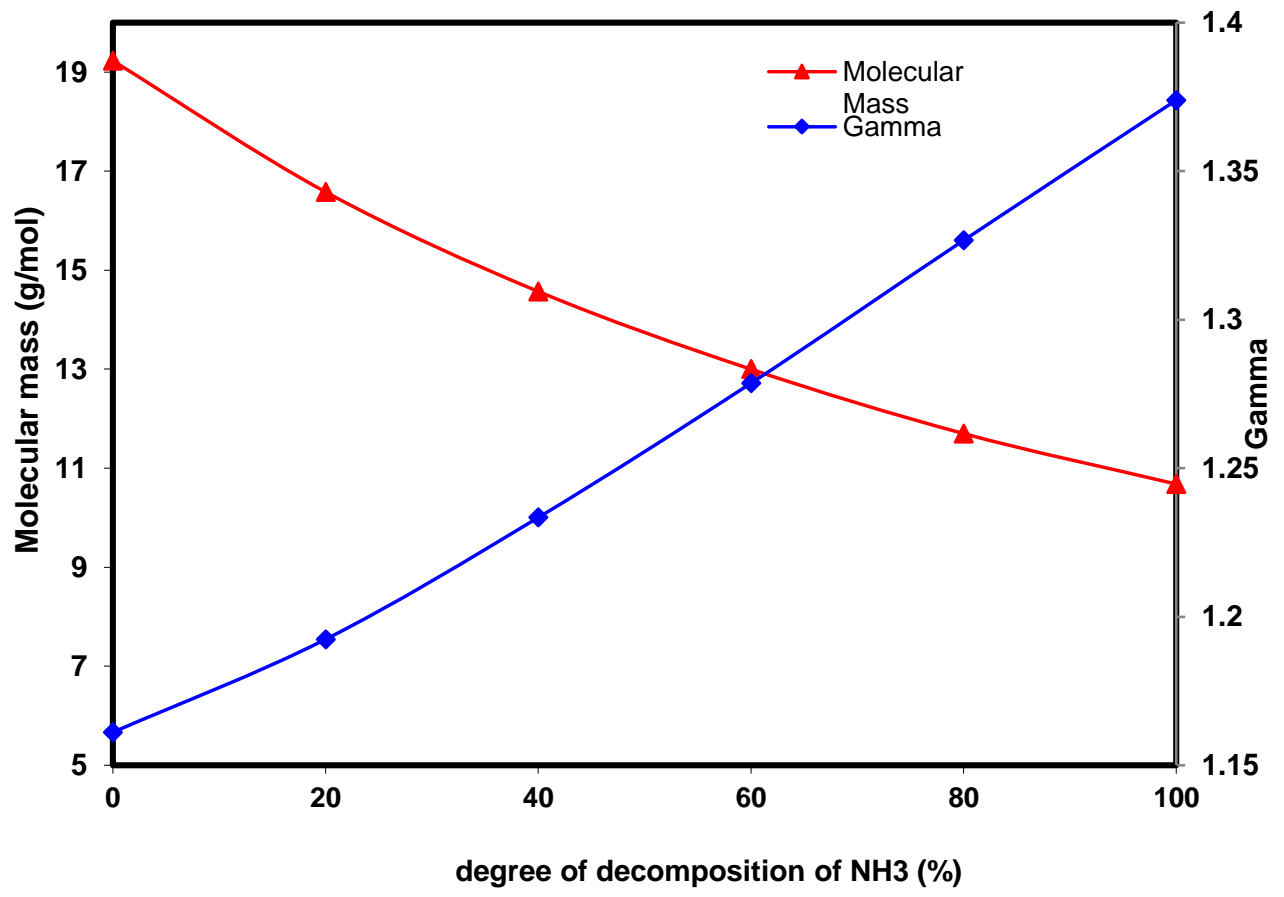

Figure 14. Variation of molecular mass and $\gamma$ with the degree of decomposition of ammonia.

Figure 15 shows the decomposition products of hydrazine as function of the degree of decomposition of ammonia. The results obtained are compared with previous researches presented in the reference (Sutton, 1992). The comparison shows a good agreement where the difference is less than $2 \%$. 


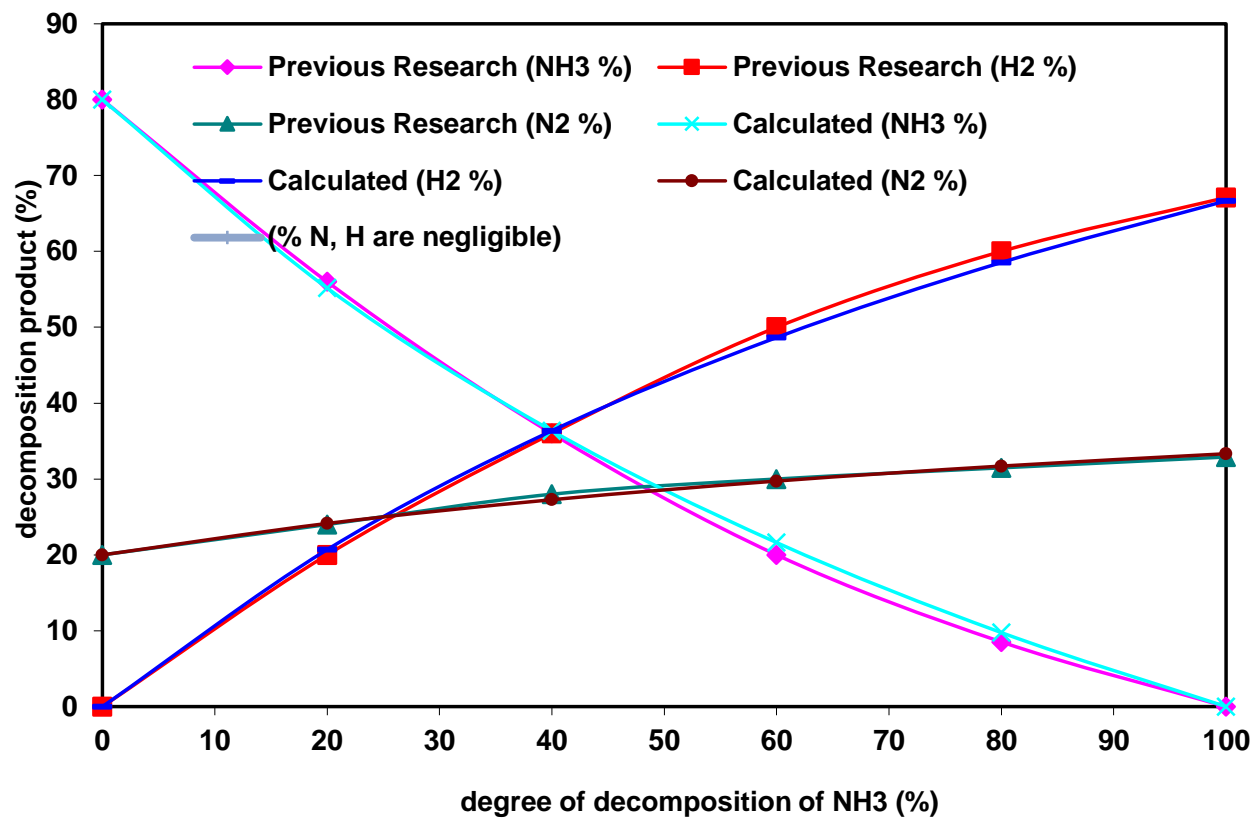

Figure 15. Variation of the decomposition products with the degree of decomposition of ammonia.

\section{Hydrogen Peroxide $\left(\mathrm{H}_{2} \mathrm{O}_{2}\right)$ Monopropellant}

For $\mathrm{H}_{2} \mathrm{O}_{2}$ monopropellant results, figures 16 and 17 present, the variations of the specific impulse, the decomposition temperature, $\mathrm{C}^{*}$, molecular mass, the isentropic parameter $(\gamma)$ and the decomposition products as a function of the hydrogen peroxide concentration. The curves show that more the hydrogen peroxide concentration increases, the system will be with higher performance. This effect is explained by the fact that for a high concentration, a large quantity of $\mathrm{H}_{2} \mathrm{O}_{2}$ is decomposed, which increases the enthalpy of the reaction, and consequently the decomposition temperature. 


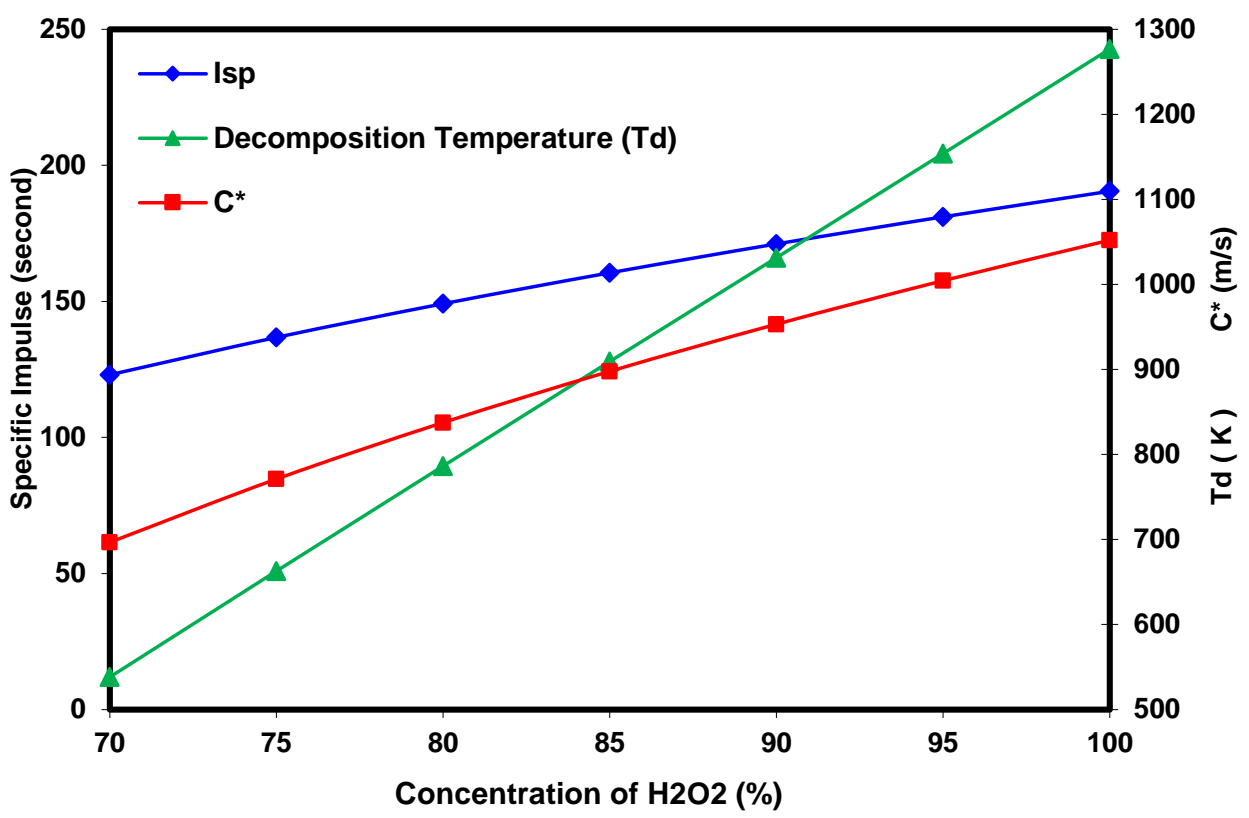

Figure 16. Variation of the decomposition temperature, specific impulse and $\mathrm{C}^{*}$ with $\mathrm{H}_{2} \mathrm{O}_{2}$ concentration.

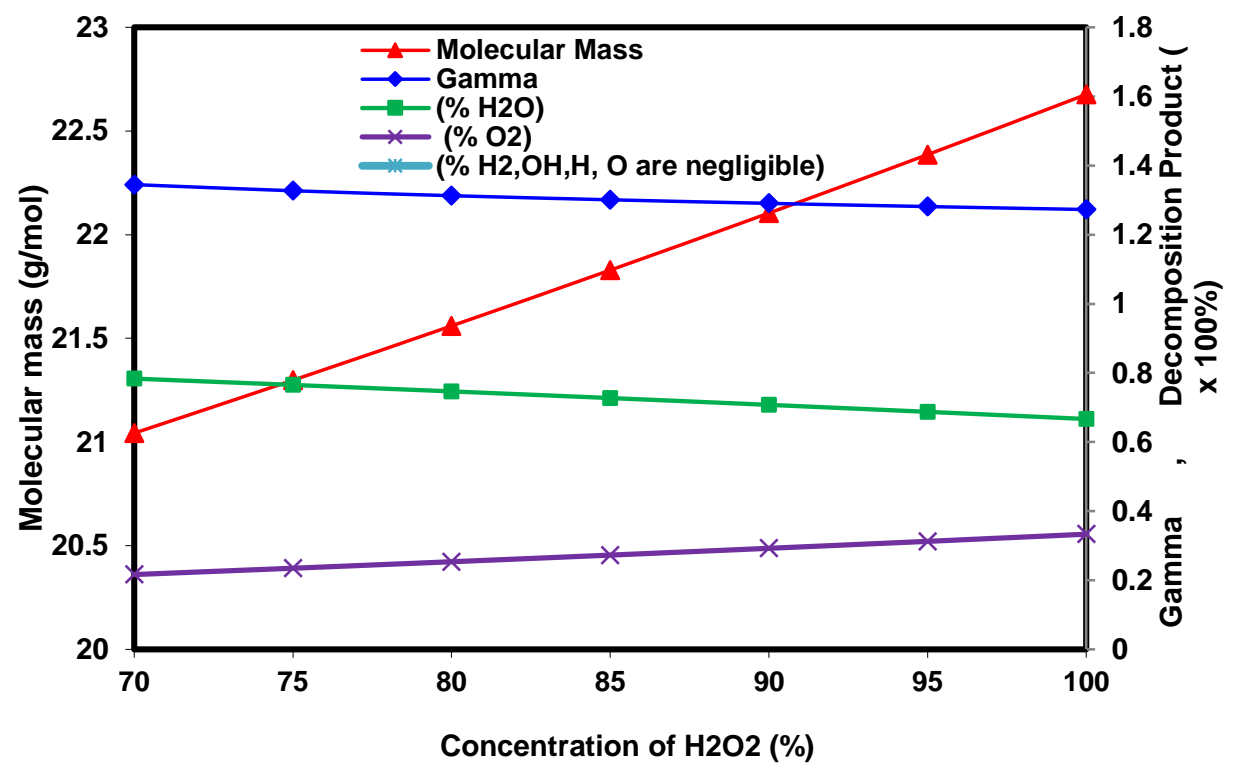

Figure 17. Variation of molecular mass, $\gamma$ and the decomposition products with $\mathrm{H}_{2} \mathrm{O}_{2}$ concentration. 


\section{Nitrous Oxide ( $\left.\mathbf{N}_{2} \mathrm{O}\right)$ Monopropellant}

Figures 18 and 19 present the variations of the specific impulse, the decomposition temperature $\left(\mathrm{T}_{\mathrm{d}}\right), \mathrm{C}^{*}$, molecular mass, the isentropic parameter $(\gamma)$ and the decomposition products as a function of degree of the decomposition of $\mathrm{N}_{2} \mathrm{O}$. These curves show that all the parameters (specific impulse, percentages of $\mathrm{N}_{2}$ and $\mathrm{O}_{2}$, temperature $\mathrm{T}_{d}$ ) increase with the degree of decomposition of $\mathrm{N}_{2} \mathrm{O}$, and this is because the decomposition of $\mathrm{N}_{2} \mathrm{O}$ releases an energy in the form of heat.

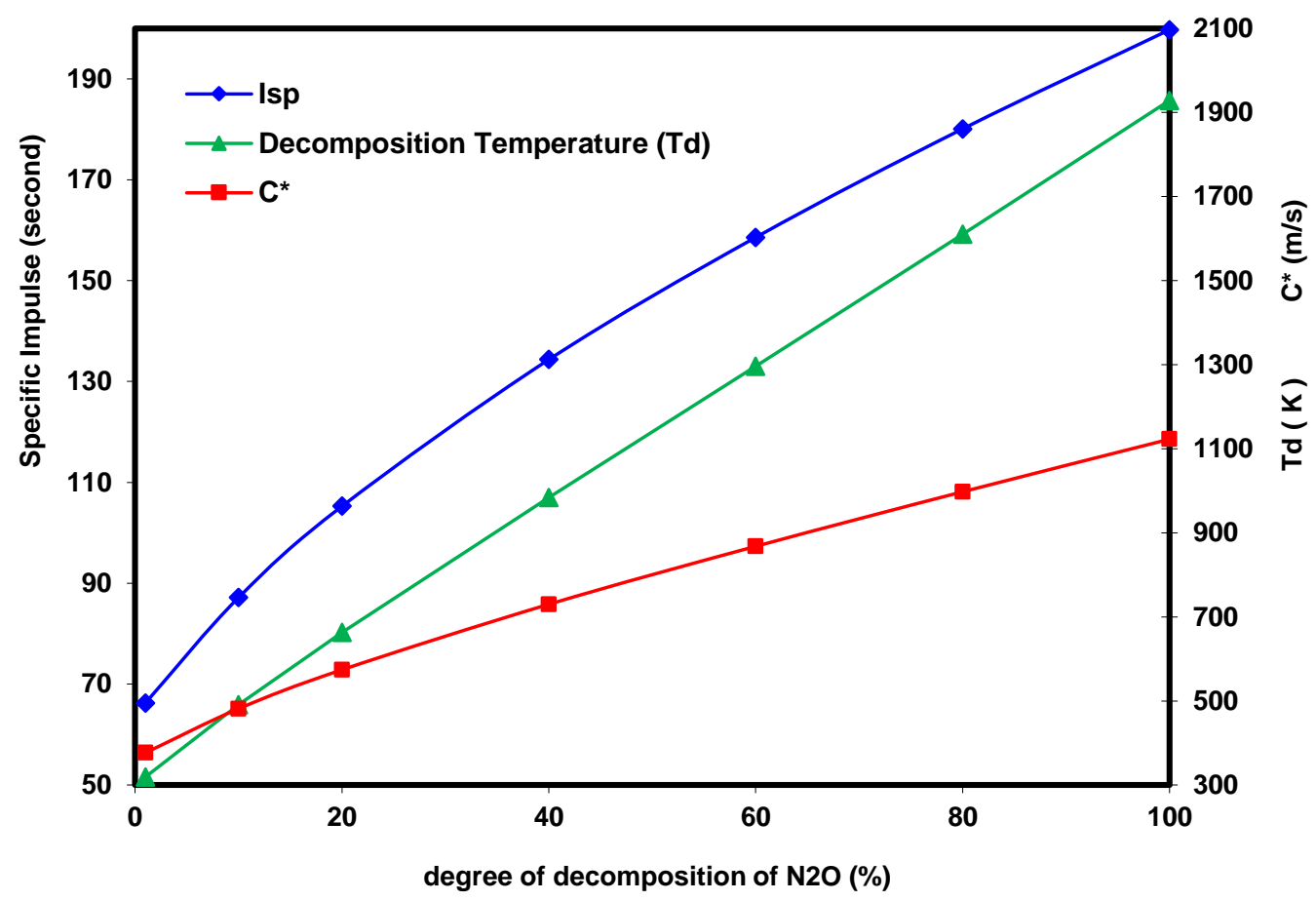

Figure 18. Variation of the decomposition temperature, specific impulse and $\mathrm{C}^{*}$ with the degree of decomposition of $\left(\mathrm{N}_{2} \mathrm{O}\right)$. 


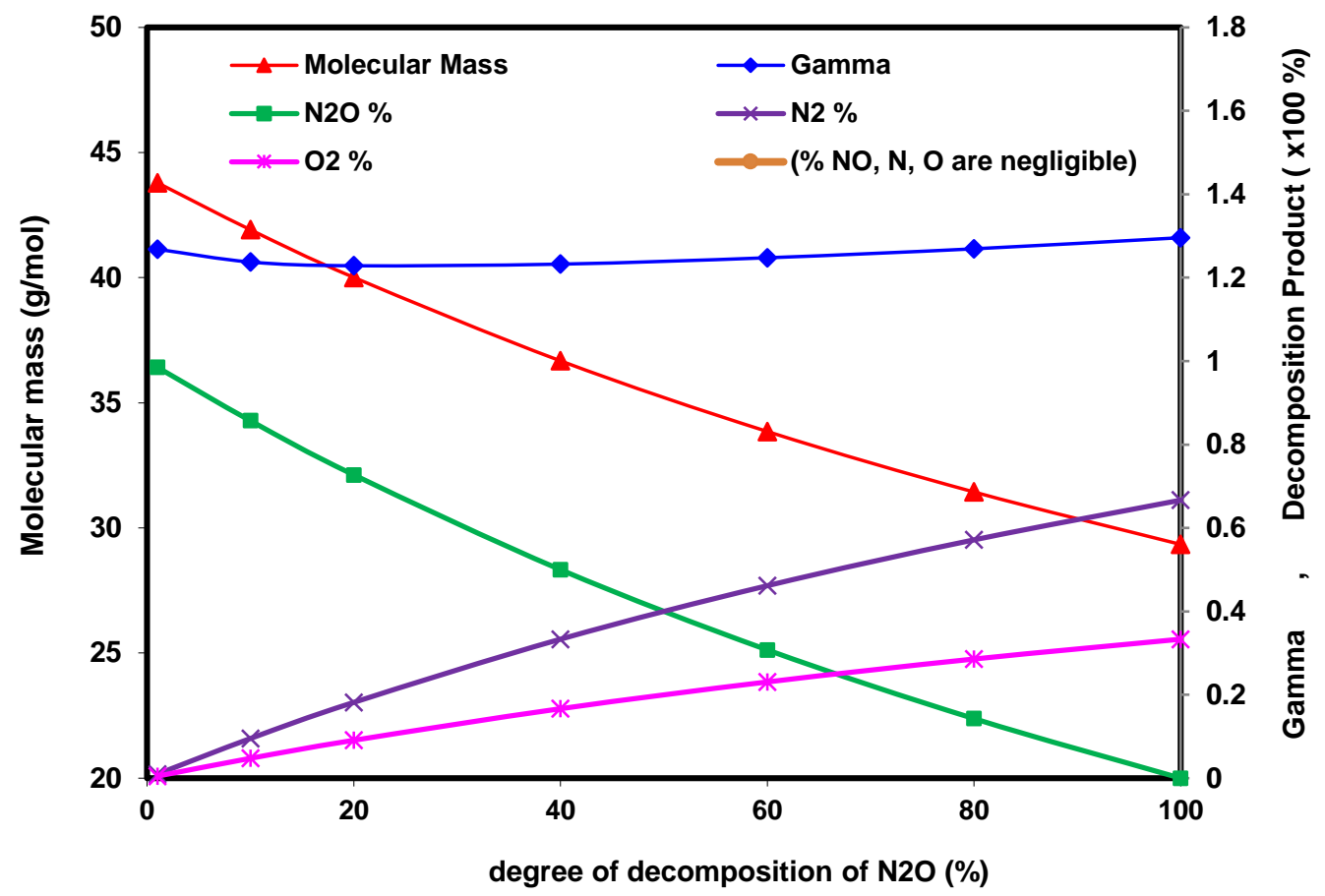

Figure 19. Variation of molecular mass, $\gamma$ and the decomposition products with the degree of decomposition of $\left(\mathrm{N}_{2} \mathrm{O}\right)$.

\section{Application}

Hydrogen peroxide monopropellant thruster developed at Surrey Satellite Technology Limited (SSTL) has been taken as an example for the simulation. This work is one of the studies performed for the development of new propulsion systems for future satellite missions using green propellants. The design is based on hydrogen peroxide as propellant and pure silver catalyst (Amri et al., 2013). Table 3 gives the geometrical and thermodynamic parameters. Table 4 gives the results (specific impulse and thrust) obtained compared to the experimental values (using 100 silver mesh disks catalyst). 
Table 3

Geometrical and Thermodynamic Parameters of $\mathrm{H}_{2} \mathrm{O}_{2}$ Monopropellant

\begin{tabular}{|l|l|l|l|}
\hline \multicolumn{2}{|c|}{ Geometrical parameters } & \multicolumn{2}{c|}{ Thermodynamic parameters } \\
\hline $\begin{array}{l}\text { Thruster } \\
\text { manufacturer }\end{array}$ & SSTL-CTS & Propellant & Hydrogen peroxide \\
\hline $\begin{array}{l}\text { Chamber diameter } \\
(\mathrm{mm})\end{array}$ & 10.00 & $\begin{array}{l}\text { chamber pressure } \\
\text { (bar) }\end{array}$ & 17.0 \\
\hline $\begin{array}{l}\text { Throat diameter } \\
(\mathrm{mm})\end{array}$ & 0.8 & $\begin{array}{l}\text { Tank temperature } \\
(\mathrm{K})\end{array}$ & 300 \\
\hline $\begin{array}{l}\text { Nozzle expansion } \\
\text { ratio }\end{array}$ & $100: 1$ & Catalyst & Silver catalyst \\
\hline
\end{tabular}

Table 4

$\mathrm{H}_{2} \mathrm{O}_{2}$ Monopropellant Results

\begin{tabular}{|l|c|c|}
\hline & Calculated & Experimental \\
\hline Thrust $(\mathrm{mN})$ & 1.5033 & 1.4 \\
\hline $\begin{array}{l}\text { Specific impulse } \\
\text { (second) }\end{array}$ & 171.01 & 170 \\
\hline
\end{tabular}

\section{Propulsion System Study}

It is very important to study all the system during its lifetime, including the depressurization during propellant consumption (blow down mode as shown in figures 1(a) and 12(a). In general, liquid propellant is pressurized via a pressurant gas, the propellant and the pressurant are separated by means of an elastomer. In our study, nitrogen and helium pressurants have been selected for the pressurization of liquid propellants. As an example of propulsion systems, studies for small satellites, the following cases have been selected:

- Inputs for thermal propulsion system: Alsat-1 thruster (Amri \& Gibbon, 2012), 5 liters tank volume, 50 watts resistojet power and ambient storage temperature.

- Inputs for monopropellant system: hydrogen peroxide thruster (Amri et al., 2013), 5 liters tank volume, gas nitrogen as pressurant with $20 \%$ ullage, ambient storage temperature. Storage pressure of the propellants are as follow (Zakirov, 2001):

- Tank pressure of 200 bar for $\mathrm{N} 2, \mathrm{He}, \mathrm{H} 2, \mathrm{O} 2$ and $\mathrm{CH} 4$,

- Tank pressure of 50 bar for $\mathrm{N} 2 \mathrm{O}$ and xenon,

- Tank pressure of 22 bar for hydrogen peroxide and hydrazine monopropellants. The results of depressurization and thrust level as a function of filling ratio by mass are presented in figures 20, 21, and 22. 
International Journal of Aviation, Aeronautics, and Aerospace, Vol. 7 [2020], Iss. 3, Art. 10

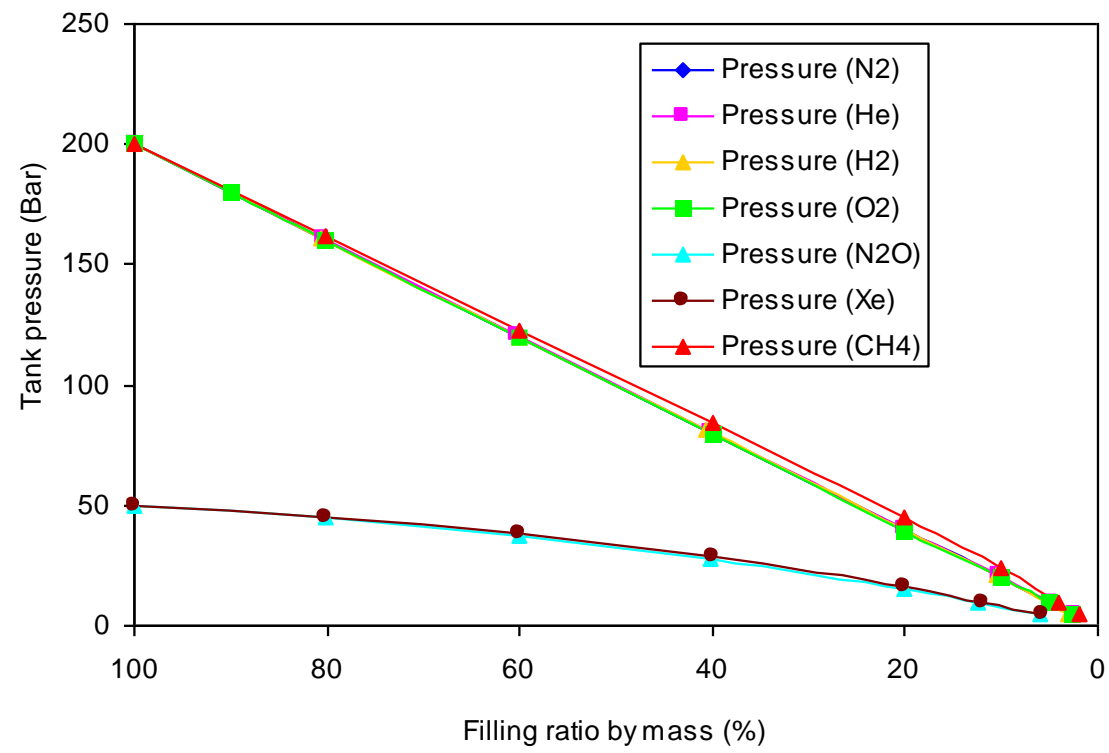

Figure 20. Tank pressure as a function of filling ratio by mass for thermal propulsion.

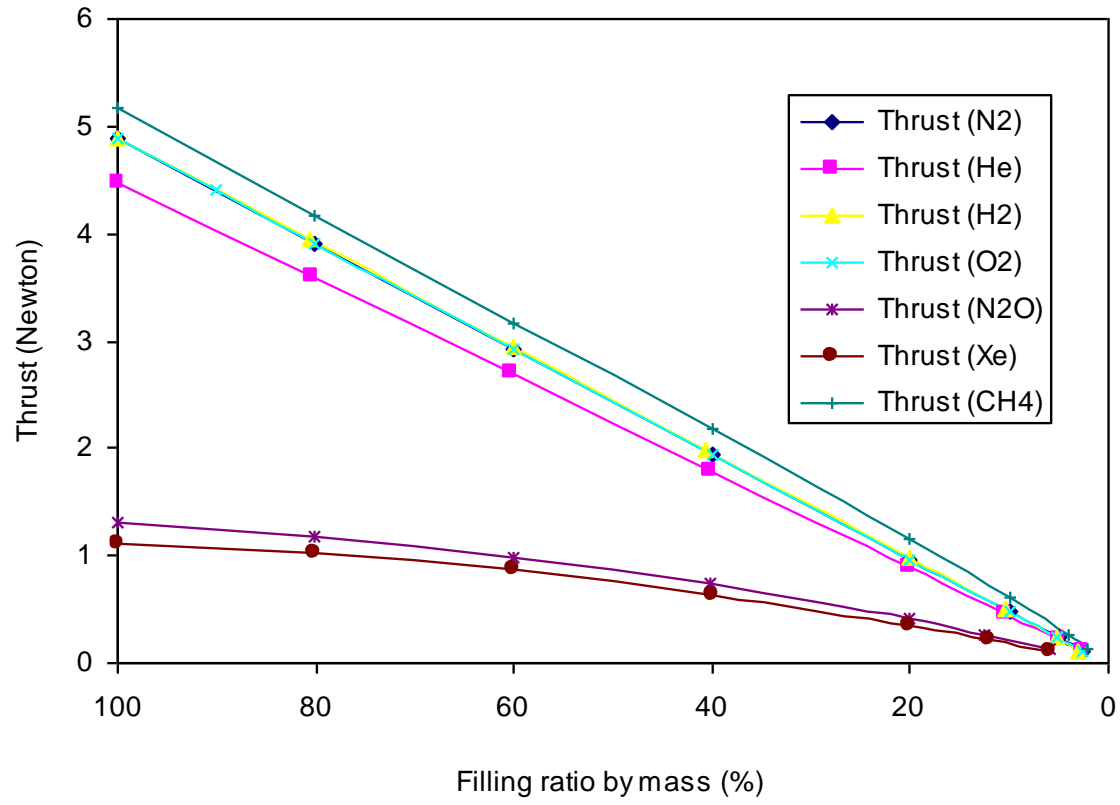

Figure 21. Thrust level as a function of filling ratio by mass for thermal propulsion. 


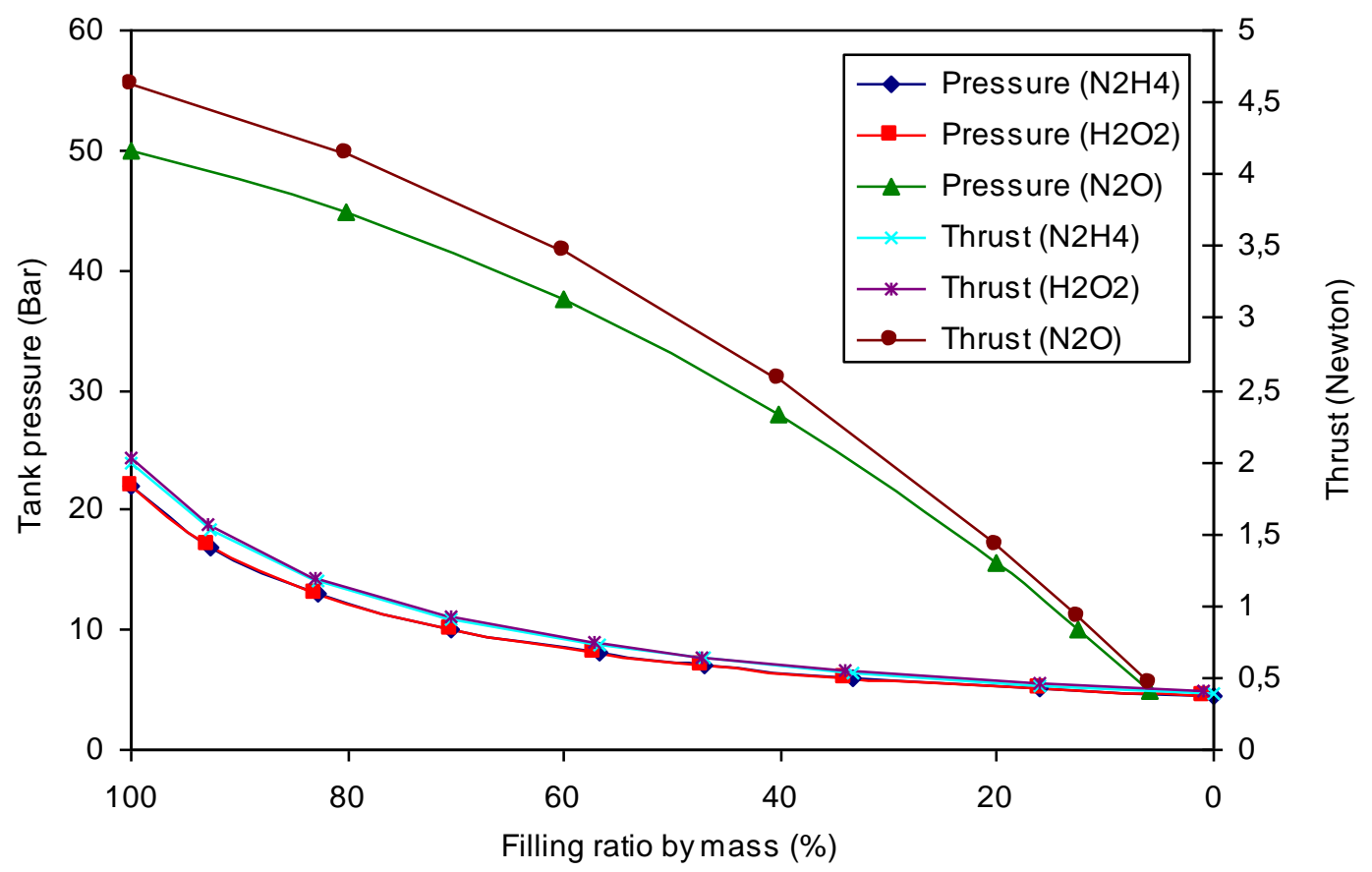

Figure 22. Tank pressure and thrust level as a function of filling ratio by mass for monopropellants.

The system in an unregulated pressure mode (blow down mode) is the most used schematic for small satellite propulsion systems, and this is due to its simplicity, less propulsion components and low cost. In this configuration, the thruster is connected directly to the propellant in the tank. As the thrust level is directly proportional to the tank pressure, the thrust decreases as the tank pressure decreases during the lifetime of the system.

\section{Conclusions}

This paper has studied low thrust propulsion systems. The propulsion systems taken into account are: cold gas, thermal and monopropellant systems with the most propellants that can be used for these systems. Methods of study and some results were presented for each system. In comparison with cold gas propulsion, it is clear that to increase the specific impulse for thermal propulsion, it is necessary to give to this last a higher electric power. Some results for the performance of hydrazine $\left(\mathrm{N}_{2} \mathrm{H}_{4}\right)$, hydrogen peroxide $\left(\mathrm{H}_{2} \mathrm{O}_{2}\right)$ and nitrous oxide $\left(\mathrm{N}_{2} \mathrm{O}\right)$ monopropellants are given. As an application, 15 watts butane thruster and hydrogen peroxide monopropellant thruster have been analyzed and compared to real values. The comparison shows good agreement. 


\section{Acknowledgments}

The authors wish to thank the Aeronautical Department of University of Blida and the Centre of Satellite Development (CDS) for their support to perform this work and ALSAT-1 project manager, Mr. Mohamed Bekhti and Professor. Y.Bentoutou. 


\section{References}

Amri, R., \& Gibbon, D. (2012). In orbit performance of butane propulsion system. Advances in Space Research, 49, 648-654.

Amri, R., \& Rezoug, T. (2011). Numerical study of liquid propellants combustion for space applications. Acta Astronautica, 69, 485-498.

Amri, R., Gibbon, D., \& Rezoug, T. (2013). The design, development and test of one newton hydrogen peroxide monopropellant thruster. Aerospace Science and Technology, 25, 266-272.

Braker, W., \& Mossmann, A. L. (1973). Matheson gas data book (6th ed.). Chicago, IL: Searle.

Gibbon, D., Underwood, C., Sweeting, M., \& Amri, R. (2002). Cost effective propulsion systems for small satellites using butane propellant. Acta Astronautica, 51(1-9), 145-152.

Jo, S. (2017). Response characteristics of H2O2 monopropellant thrusters with MnO2-mixed PbO catalyst. Aerospace Science and Technology, 60, 1-8.

Leomanni, M., Garulli, A., Giannitrapani, A., \& Scortecci, F. (2017). Propulsion options for very low earth orbit microsatellites. Acta Astronautica, 133, 444-454.

Moon, Y., \& Kwon, S. (2014). Lunar soft landing with minimum-mass propulsion system using $\mathrm{H}_{2} \mathrm{O}_{2}$ /kerosene bipropellant rocket system. Acta Astronautica, 99, 153-157.

Sutton, G. P. (1992). Rocket propulsion elements (6th ed.). New York, NY: John Wiley \& Sons.

Van Wylen, G. J. (1973). Fundamentals of classical thermodynamics. New York, NY: John Wiley \& Sons.

Zakirov, V., Sweeting, M. N., Lawrence, T., \& Sellers, J. (2001). Nitrous oxide as a rocket propellant. Acta Astronautica, 48(5-12), 353-362. 